\title{
An Investigation of Different Strategies for Thermo-mechanical Rolling of Structural Steel Heavy Plates
}

\author{
Mikael JONSSON \\ SSAB Oxelösund Ltd. GVT SE-613 80 Oxelösund, Sweden. E-mail: mikael.jonsson@ssabox.com
}

(Received on February 10, 2006; accepted on June 6, 2006)

\begin{abstract}
A software has been developed to determine optimal rolling passes in thermo-mechanical (TM) rolling in order to obtain a fine microstructure. It includes models of the effect of strain, precipitates, static and dynamic recrystallization and austenite grain size on the final grain size. It was also used to study the effect of different long interpass times during thermo-mechanical rolling of heavy plates. The predicted grain sizes for four different cases were compared with experimental results.
\end{abstract}

KEY WORDS: plate; thermo-mechanical rolling; recrystallization; rolling strategy; grain size; precipitation; pass schedule generation.

\section{Introduction}

High-strength structural steel plates with yield strength up to $500 \mathrm{MPa}$ can be produced with thermo-mechanical (TM) rolling and accelerated cooling immediately after the rolling ${ }^{1)}$ giving a fine grained material with good ductility and a high strength. ${ }^{2}$ ) There is a great potential for energy saving by optimization of the TM process, since no reheat quenching tempering process is needed. Furthermore, the weldability of the plate becomes very good as the chemical composition of the plate can be kept at a low level. ${ }^{1)}$ The grain refinement is obtained by substantial thickness reductions at decreased rolling temperature. The TM process includes a long interpass time during the pass schedule. ${ }^{3)}$ The long interpass time before the final passes triggers recrystallization and thereby promotes a final structure of fine grains.

The aim of this work was to develop a pass schedule planning software on basis of the microstructural evolution in the steel during TM rolling. Knowledge of the rolling parameters and process limitations associated with the TM rolling makes it possible to design proper rolling schedules for obtaining a good end product and acceptable productivity.

A common method to generate pass schedules for TM rolling is to limit the temperature in the last pass. The strategy to control the rolling process proposed in this paper is based on predicted grain size instead of temperature only. The developed code for the microstructure behavior accounts for recrystallization, austenite grain size, contents of niobium and titanium and precipitation. The simulated austenite grain sizes show good agreement, compared to results from full-scale experiments.

\section{Method}

\subsection{Overall Logic in the Pass Schedule Generator}

A Visual Basic program was developed for simulation of microstructure during a pass schedule. The program simulates a complete pass schedule for rolling of a heavy plate in the four-high mill at SSAB Oxelösund. The program determines the reduction in each pass and also specifies the long interpass time in order to obtain a fine final microstructure. The required CPU-time is around $5 \mathrm{~min}$ for simulating a complete TM pass schedule.

The overall logic is shown in Fig. 1. The program attempts to reduce the thickness by $50 \%$ in each pass without exceeding available force and torque with a profile within the tolerances. If this is not achieved, then a smaller reduction is tried. The generator strives for reaching the target thickness $h_{\mathrm{tar}}$. The roll force model gives roll force and torque. CROWN426 is a program package for simulating thickness profile and flatness in flat rolling. The elastic deformation of rolls and the deformation of the rolled material are calculated for both hot and cold rolling mills with 2-6 rolls. Force distributions between rolls and work roll profile are calculated. The assumed reduction together with the prediction of profile by CROWN 426 gives the accumulated plastic strain. The latter program is only used when the thickness is below $80 \mathrm{~mm}$. STEELTEMP ${ }^{\circledR} 2 \mathrm{D}$ is a program for temperature and heat-transfer analysis during casting, cooling, stripping, heating, rolling and forging. Temperatures and densities of heat flow rate are calculated in a cross section of the steel. The temperature evolution during and between the roll passes is computed by STEELTEMP ${ }^{\circledR}$ in this investigation. The lengths of the interpass times are in the range of 5-15[s] and depend on the practical handling of the plates. Thus they depend on the length of the plate, and are known from common rolling schedules and tabulated in the program. The plate is rotated between the 


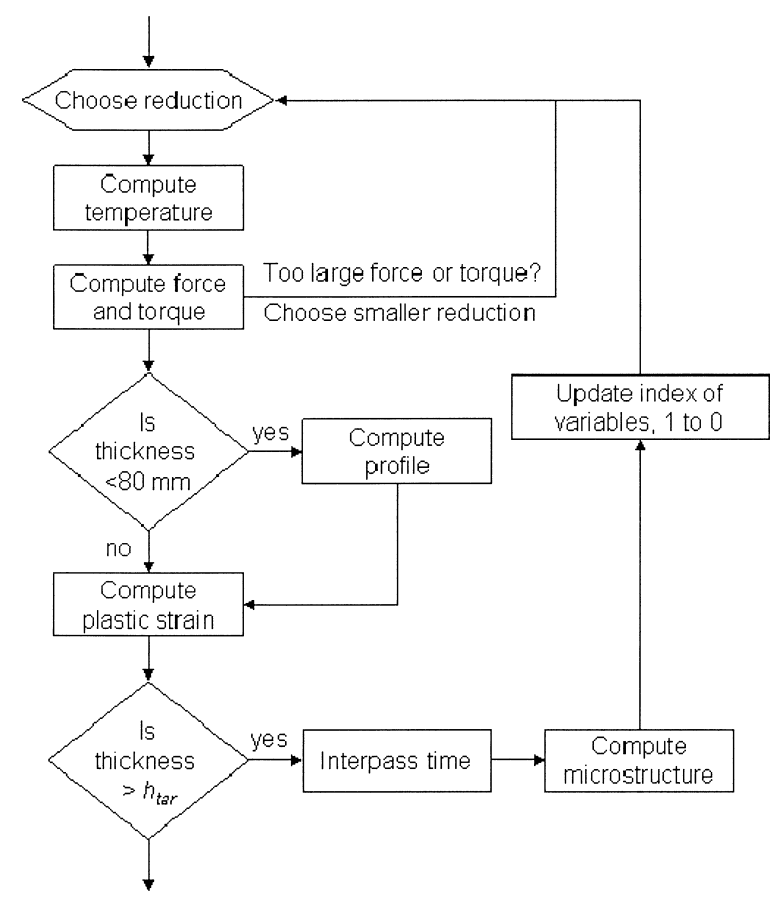

Fig. 1. The flow chart for each rolling pass of the roll pass schedule generator.

initial passes but not after the 4th pass and it is cooling slowly also during these initial passes as it is quite thick. Therefore the long interpass time is not placed until after the fourth pass. Its length is never allowed to exceed $10 \mathrm{~min}$ for productivity reasons. The scheduler determines appropriate length of the long interpass time. The scheduler currently chooses only between one, five or ten minutes. It is possible to find the exact optimum that minimizes the final grain size by optimization. The limitation currently imposed by choosing between a given set of times is made in order to limit the calculation time. The microstructure model uses the temperature and deformation to predict the microstructure. The roll-force and microstructure model are described below whereas STEELTEMP is described in Ref. 4) and CROWN 426 in Ref. 5). Subscripting is used for some of the variables in the following description of the theory implemented in the roll pass scheduler and summarized in Fig. 1. Subscript 0 , [ $]_{0}$, means entry value to a pass and subscript $1,[]_{1}$, means exit value after the pass. Thus the exit values become entry values after each roll pass is analysed.

\subsection{Model for Rolling Force}

The roll force $F[\mathrm{~N}]$ model used by the roll pass generator is

$$
F=1.15 \sigma_{\mathrm{y}} L_{\mathrm{d}} b k_{\text {Pawelski }}=1.15 \sigma_{\mathrm{y}} L_{\mathrm{d}}\left(\frac{b_{0}+b_{1}}{2}\right) k_{\text {Aspect ratio }}
$$

where 1.15 is a correction factor due to plane strain assumption, $L_{\mathrm{d}}[\mathrm{mm}]$ is the contact length between the work roll and the material including the effect of roll flattening, $b[\mathrm{~mm}]$ is the mean width of the entry width $b_{0}$ and the exit width $b_{1}$ and $k_{\text {Aspect ratio }}[-]$ is a correction factor for friction and inhomogeneous deformation. ${ }^{6}$
The spread is calculated with the method derived by Beese $^{8)}$ for commercial rolling of low carbon steel slabs

$$
b_{1}=b_{0}\left(\frac{h_{0}}{h_{1}}\right)^{0.6 \frac{h_{0}}{b_{0}} \exp \left(-0.32 \frac{h_{0}}{L_{\mathrm{d}}}\right)}
$$

$h_{0}$ and $h_{1}$ is the entry and exit thicknesses [mm], respectively.

The flow stress $\sigma_{\mathrm{y}}[\mathrm{MPa}]$ is determined with the modified Misaka equation $^{7)}$

$$
\begin{aligned}
\sigma_{\mathrm{y}}= & g \cdot e^{\left(0.126-1.75 C+0.594 C^{2}+\frac{2851+2968 C-1120 C^{2}}{T}\right)} \\
& \times\left(\frac{\varepsilon_{0}^{\mathrm{p}}+\varepsilon_{1}^{\mathrm{p}}}{2}\right)^{0.21}\left(\dot{\varepsilon}_{1}^{\mathrm{p}}\right)^{0.13} f \ldots \ldots \ldots \ldots \ldots \ldots \ldots \ldots \ldots \ldots \ldots \ldots \ldots \ldots
\end{aligned}
$$

where $g$ is the constant of gravity $9.8[\mathrm{~N} / \mathrm{kg}]$ needed to convert the units from $\left[\mathrm{kg} / \mathrm{mm}^{2}\right]$ to $[\mathrm{MPa}], C$ is the carbon content in weight percentage $[\%], \varepsilon_{0}^{\mathrm{p}}[-]$ is the entry plastic strain in the pass, $\varepsilon_{1}^{\mathrm{p}}$ is the exit strain from the roll gap:

$$
\varepsilon_{1}^{\mathrm{p}}=\ln \left(\frac{h_{0}}{h_{1}}\right)+\varepsilon_{0}^{\mathrm{p}}
$$

$\varepsilon_{1}^{\mathrm{p}}[1 / \mathrm{s}]$ is its strain rate, $T[\mathrm{~K}]$ is the absolute temperature. The factor $f[-]$ is a correction function of the contents of alloying elements niobium $\mathrm{Nb}$, manganese $\mathrm{Mn}$, and titanium $\mathrm{Ti}$, all in weight percentage [\%]. This value is computed as

$$
f=1.15 \cdot(0.768+0.51 \mathrm{Nb}+0.137 \mathrm{Mn}+4.217 \mathrm{Ti}) \ldots
$$

The factor 1.15 in Eq. (5) is based on statistics from measurements of the rolling force in Oxelösund. The reason is that the used steel grades also contain other alloying elements such as chrome, vanadium, molybdenum and nickel. The exit plastic strain computed by Eq. (4) may be modified, as described later, in case recrystallization occurs.

\subsection{Modeling of the Microstructure}

The grain size evolution is calculated by a microstructure model. The complete flow chart for the microstructure model is shown in Fig. 2.

The effective plastic strain and plastic strain rate together with temperature are driving the changes in grain size. The model is accounting for grain growth as well as recrystallization.

There are many reports giving grain sizes for micro-alloyed steels after reheating. This grain size is the initial value for the roll pass scheduler. Köthe ${ }^{3)}$ reported that the grain size is below $100 \mu \mathrm{m}$ at $1250^{\circ} \mathrm{C}$. Zheng and co-work$\mathrm{ers}^{14)}$ stated that $200 \mu \mathrm{m}$ is a good approximation for a $\mathrm{V}-\mathrm{Ti}$ steel after $1 \mathrm{~h}$ reheating at $1170^{\circ} \mathrm{C}$. Hong and Park ${ }^{20)}$ used $200 \mu \mathrm{m}$ in their investigation. The initial grain size before the rolling is taken as $200 \mu \mathrm{m}$ in the current work Furthermore, it is assumed that there exists no precipitation of $\mathrm{Nb}(\mathrm{C}, \mathrm{N})$ or accumulated plastic strain in the beginning.

Recrystallization can be prevented by strain induced precipitation. Thus the program starts with computing the amount of precipitation. If too much precipitation has occurred, then there will be no recrystallisation else it is de- 


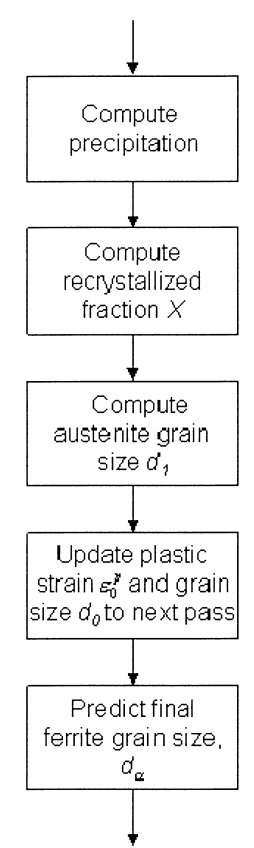

Fig. 2. The flow chart of the microstructure model.

termined whether the recrystallization is metadynamic (MDRX) or static (SRX). Thereafter the effect of recrystallization on the accumulated plastic strain and grain size is computed. Grain growth is only computed after recrystallization is complete. Finally, it is predicted what the final microstructure, ferrite grain size, would become if the plate is cooled to room temperature in the current state. The details of the model are explained below.

\subsubsection{Precipitation Model}

Significant strain induced precipitation effectively stops SRX that might occur during the short time for the reduction during the rolling. ${ }^{25)}$ Abad et al. ${ }^{11)}$ established that the precipitation needed to reach $5 \%$ completion in order to be effective to prevent SRX. Hence, it is assumed that if 5\% precipitation is reached then no SRX occurs.

The Dutta and Sellars model ${ }^{25)}$ describes the strain-induced precipitation from supersaturated austenite, under isothermal conditions. Since the model was derived under isothermal conditions, the additivity rule ${ }^{11)}$ was employed to enable its application during cooling. The criterion for $5 \%$ precipitation is written as

$$
\sum_{T_{0}}^{T_{1}} \frac{\Delta t}{t_{0.05 \mathrm{~m}}\left(T_{j}\right)}=1
$$

where $\Delta t$ is the time increment the cooling curve is divided into. It is taken as $0.1 \mathrm{~s}$. Furthermore, $t_{0.05 \mathrm{~m}}\left(T_{j}\right)$ is the time needed for $5 \%$ precipitation at temperature $T_{j}$. The left hand side is accumulated over all roll passes. Siciliano and Jonas ${ }^{9)}$ concluded that the time for $t_{0.05 \mathrm{~m}}$, for steel with additions of Mn and Si should be

$$
t_{0.05 \mathrm{~m}}=\frac{t_{0.05 \mathrm{p}}}{10^{(-0.26-0.90 M n+2.855 S i)}}
$$

where $t_{0.05 \mathrm{p}}$ is the corresponding time for the isothermal strain-induced precipitation of $\mathrm{Nb}(\mathrm{C}, \mathrm{N})$ according to ${ }^{9,25)}$

$$
\begin{array}{r}
t_{0.05 \mathrm{p}}=\frac{\left(\left(\frac{M n}{S i}\right)^{0.42} e^{\frac{0.42 N b}{C}}\right)}{169400}[N b]^{-1} \frac{1}{\varepsilon_{1}^{\mathrm{p}}}\left(\dot{\varepsilon}_{1}^{\mathrm{p}} e^{\frac{Q_{\text {def }}}{R T}}\right)^{-0.5} \\
\times e^{\frac{Q_{\mathrm{di}}}{R T}} e^{\frac{B}{T^{3}\left(\ln \left(K_{\mathrm{s}}\right)\right)^{2}}} \ldots \ldots \ldots \ldots \ldots \ldots \ldots \ldots \ldots \ldots \ldots \ldots \ldots \ldots \ldots
\end{array}
$$

where $R$ is the gas molar constant $8.314[\mathrm{~J} / \mathrm{mol} / \mathrm{K}]$ and $T$ is temperature [K]. $B, Q_{\mathrm{def}}$ and $Q_{\mathrm{di}}$ are constants, $B=2.5 \cdot 10^{10}$ $\left[\mathrm{K}^{3}\right], Q_{\text {def }}=400[\mathrm{~kJ} / \mathrm{mol}]^{11,25)}, Q_{\mathrm{di}}=270[\mathrm{~kJ} / \mathrm{mol}] .^{9,25)} . K_{\mathrm{s}}$ is the supersaturation ratio proposed by Irvine ${ }^{27)} K_{\mathrm{s}}$ decides the driving force for precipitation. $K_{\mathrm{s}}$ can be obtained by ${ }^{9)}$

$$
K_{\mathrm{S}}=\frac{10^{2.26-\frac{838 M n^{0.246}-1730 S i^{0.594}-6440}{T_{\mathrm{rh}}}}}{10^{2.26-\frac{838 M n^{0.246}-1730 \mathrm{Si}^{0.594}-6440}{T}}}
$$

where $T_{\mathrm{rh}}$ is the reheat temperature [K] applied before the plate is rolled.

\subsubsection{Recrystallization and Grain Growth}

The model first determines whether MDRX occurs during the reduction and also SRX after the rolling pass. $X$ denotes the recrystallized fraction of the material. The grain growth is assumed to start when the recrystallisation is complete, taken as $X>0.99$.

This recrystallized fraction of the material will have a low plastic strain. The fraction that recrystallized during a pass should then be followed separately with its own accumulated plastic strain. This is avoided in the current work in order to have an efficient model. The plastic strain computed according to Eq. (4) is therefore reduced as described below when recrystallization occurs. This is compensated by resetting $X$ to zero after each roll pass, since the material is plastic deformed and the recrystallization starts from these new conditions. The plastic strain is assumed to be homogeneous over the cross section in every pass, the cross section is numerical treated as one fraction.

A more detailed model would follow the recrystallized fraction in each pass during later passes and with separate tracing of the plastic strain in this fraction.

The factors that determine influence on the recrystallization are steel grade, temperature, strain rate, strain and current grain size. ${ }^{13)}$ The evolution of the recrystallisation is assumed to follow the Avrami equation:

$$
X=1-e^{\left(-0.693\left(\int \frac{d t}{t_{0.5}}\right)^{n}\right)}
$$

where $t_{0.5}$ is the time for $50 \%$ for SRX or MDRX and $n$ is a constant. For static recrystallization ${ }^{11)} n$ is 1 , and 1.06 for metadynamic recrystallization. ${ }^{17)}$ Each of the models are evaluated and their contributions to $X$ are added. The additivity rule was shown in Ref. 11) to be a good approximation for solving the equation, since the plate cools down in the interpass times and the equations for $t_{0.5}$ are derived under isothermal conditions. The cooling curve is divided into steps each with constant temperature and the integral is taken over the roll pass time. The time steps are 0.001 [s] for MDRX and 0.1 [s] for SRX.

The $t_{0.5}$ in Eq. (10) is different for SRX and MDRX. The 
change in temperature during the interpass time is considered in the expressions using the temperature, but not the change of any further parameters in these expressions. The time for $50 \%$ MDRX, $t_{0.5 \mathrm{MDRX}}$ is determined by the formula derived in $^{17)}$ :

$$
t_{0.5 \mathrm{MDRX}}=6.3 \cdot 10^{-4} d_{0}^{0.4} \varepsilon_{1}^{\mathrm{p}^{-0.4}} e^{\left(\frac{Q_{\mathrm{MDRX}}}{R T}\right)}
$$

where $Q_{\mathrm{MDRX}}$ is the activation energy taken as $67[\mathrm{~kJ} / \mathrm{mol}]$ and $d_{0}[\mu \mathrm{m}]$ is the entry austenite grain size in the pass.

MDRX is assumed to occur only if $\varepsilon_{1}^{\mathrm{p}}$ exceeds a critical strain $\varepsilon_{\mathrm{c}}$ determined as ${ }^{9)}$

$$
\varepsilon_{\mathrm{c}}=\left(0.8-13 N b_{\mathrm{eff}}+112 N b_{\mathrm{eff}}^{2}\right) \varepsilon_{\mathrm{p}}
$$

where $\varepsilon_{\mathrm{p}}$ is the peak strain from a true stress-strain curve for the material. $N b_{\text {eff }}$ gives the effect of niobium.

Extensive works ${ }^{9,15-17)}$ have been done regarding the effect of niobium and titanium on the recrystallization of the austenite. The observations indicate that niobium in solid solution has a retarding effect. The effective $\mathrm{Nb}$ content is determined as ${ }^{9)}$

$$
N b_{\text {eff }}=N b-\frac{M n}{120}+\frac{S i}{94}
$$

The relation has been determined for composition ranges of $\mathrm{Nb} 0.010-0.058 \%$, Mn $0.35-1.33 \%$ and $0.01-0.23 \% \mathrm{Si}$.

The peak train $\varepsilon_{\mathrm{p}}$ was assumed for a $\mathrm{Nb}-\mathrm{Ti}$ steel ${ }^{18)}$ to be possible to compute by the relation

$$
\varepsilon_{\mathrm{p}}=3.7 \cdot 10^{-3} \frac{1+20 \cdot N b+0.02 \cdot T i}{1.78} d_{0}^{0.147} Z^{0.155}
$$

where $Z$ is the Zener-Hollomon parameter

$$
Z=\dot{\varepsilon}_{1}^{\mathrm{p}} e^{\frac{Q}{R T}}
$$

where the deformation activation energy $Q$ is $325[\mathrm{~kJ} / \mathrm{mol}]$.

The static recrystallization occurs between the rolling passes provided it is not prevented by precipitation as discussed earlier. The time for $50 \% \operatorname{SRX} t_{0.5 \mathrm{SRX}}$ for a Nb-Ti steel is determined by the formula derived by Fernandez and co-workers ${ }^{16)}$

$$
\begin{aligned}
t_{0.5 \mathrm{SRX}}= & 9.92 \cdot 10^{-11} d_{0} \varepsilon_{1}^{\mathrm{p}_{1}^{\left\{-5.6 \cdot d_{0}^{-0.15}\right\}}} \dot{\varepsilon}_{1}^{\mathrm{p}^{-0.53}} \\
& \times e^{\left(\frac{180000}{R T}\right)} e^{\left(\frac{275000}{T}-185\right)(\mathrm{Nb}+0.374 \cdot \mathrm{Ti})}
\end{aligned}
$$

The grain size is affected by the recrystallization and grain growth. The latter is only applied when the recrystallisation is complete. It is possible to have a partially recrystallized microstructure after a pass if the recrystallisation is not complete when the interpass time stops. Then the new grain size $d_{1}$ is determined as an average of the entry grain size $d_{0}$ and the grain size $d_{\mathrm{MDRX} \text { or SRX }}$ of the recrystallized fraction after MDRX or SRX:

$$
d_{1}=(1-X) d_{0}+X \cdot d_{\mathrm{MDRX} \text { or SRX }}
$$

The metadynamically recrystallized grain size $d_{\mathrm{MDRX}}$ is mainly dependent on the strain rate and temperature. ${ }^{17,18)}$ According to Fernandez and co-workers, $d_{\mathrm{MDRX}}$ can be described as ${ }^{18)}$.

$$
d_{\mathrm{MDRX}}=812 \cdot Z^{-0.13}
$$

where the Zener-Hollomon parameter $Z$ is obtained from Eq. (15).

Thereafter static recrystallisation may occur. A corresponding formula as Eq. (16) is then applied where $d_{\text {MDRX }}$ is replaced by $d_{\mathrm{SRX}}$. The exit grain size $d_{\mathrm{SRX}}$ in the static recrystallized fraction computed as ${ }^{19)}$

$$
d_{\mathrm{SRX}}=K d_{0}^{\mathrm{m}} \varepsilon_{1}^{\mathrm{p}^{-v}}
$$

where $K, m$ and $v$ are material dependent constants. ${ }^{11,12,20)}$ The values are $K=1.4, m=0.56$ and $v=1$ in $^{11)}$ for $\mathrm{Nb}-\mathrm{Ti}$ steel. They are $K=1.1, m=0.67, v=0.67 \mathrm{in}^{12)}$ and $K=0.5$, $m=0.67, v=1 \mathrm{in}^{20)}$ for $\mathrm{C}-\mathrm{Mn}$-steels. In this study the values of $K, m$ and $v$ has been determined from the full-scale experiments giving $K=1.3, m=0.65$ and $v=0.67$. See the section about the full-scale experiments.

The material is assigned an entry plastic strain $\varepsilon_{1}^{\mathrm{p}}$ in the last time increment of any interpass time. This entry plastic strain is used in Eq. (4). The model is updated with following expression

$$
\varepsilon_{0}^{\mathrm{p}}=\lambda(1-X) \varepsilon_{1}^{\mathrm{p}}
$$

where $\lambda$ is a constant, reported to fall between [0.51]..$^{10,12,21)}$ In this work $\lambda=1$ is used.

Grain growth is accounted for when the recrystallization is complete $(X>0.99)$. It is assumed to follow the equation $^{10)}$ :

$$
d_{1}^{\mathrm{u}}=d_{\mathrm{MDRX} \text { or SRX }}^{\mathrm{u}}+k t e^{\left(\frac{-Q_{\mathrm{g}}}{R T}\right)}
$$

where $t[\mathrm{~s}]$ is the time after the recrystallization is completed. $Q_{\mathrm{g}}$ is the apparent activation energy for growth, $u$ is the growth exponent, and $k$ is a constant. Different values of $u$ and $k$ have been reported depending on the steel grade. ${ }^{17,22)}$ Minami and co-workers ${ }^{22)}$ set that $u=4.5$, $k=4.1 \cdot 10^{23}[1 / \mathrm{s}]$, and $Q_{\mathrm{g}}=435[\mathrm{~kJ} / \mathrm{mol}]$ for $\mathrm{Nb}$-steels. In Ref. 17), $u=7, k=1.31 \cdot 10^{18}[1 / \mathrm{s}], Q_{\mathrm{g}}=172[\mathrm{~kJ} / \mathrm{mol}]$ for SRX and $u=7, k=4.32 \cdot 10^{19}[1 / \mathrm{s}]$ and $Q_{\mathrm{g}}=217[\mathrm{~kJ} / \mathrm{mol}]$ for MDRX. Different values of $m, k$ and $Q_{\mathrm{g}}$ were tested in the pass schedule generator. Good agreement was obtained, for $u=7, k=9 \cdot 10^{25}[1 / \mathrm{s}], Q_{\mathrm{g}}=435[\mathrm{~kJ} / \mathrm{mol}]$ for both SRX and MDRX. Equation (21) was also solved with the additivity rule.

\subsubsection{Model for Final Ferrite Grain Size}

The ferrite size can be expressed as a function of the austenite grain size, retained strain, chemical composition and cooling rate. ${ }^{23)}$ The cooling rate is controlled by the amount of accelerated cooling in Oxelösund. According to Gibbs and co-workers, the strongest influence on the ferrite grain size is the amount of retained strain. ${ }^{24)}$ A relationship between the final ferrite grain size $d_{\alpha}$ and the influencing parameters is ${ }^{24)}$

$$
d_{\alpha}=\left(1-0.8 \varepsilon_{1}^{\mathrm{p} 0.15}\right)\left(29-5 \sqrt{\dot{T}}+20\left(1-e^{-0.015 \mathrm{~d}_{1}}\right)\right) . .
$$

whereis $\varepsilon_{1}^{\mathrm{p}}$ the retained strain when the cooling starts, $\dot{T}\left[{ }^{\circ} \mathrm{C} / \mathrm{s}\right]$ is cooling rate, $d_{1}[\mu \mathrm{m}]$ is the austenite grain size. The cooling rate was set to $0.5\left[{ }^{\circ} \mathrm{C} / \mathrm{s}\right]$ during the final cooling of the plate after rolling corresponding to air cooling for $70 \mathrm{~mm}$ plate and $2.5\left[{ }^{\circ} \mathrm{C} / \mathrm{s}\right]$ for $40 \mathrm{~mm}$ plate. This is the 
ferrite grain size that would be obtained if the plate with the current austenite grain size and plastic strain is cooled to room temperature.

\section{Experiments for Calibration and Validation of the Model}

\subsection{Experiments for the Austenite Grain Size}

The experiments were used to calibrate the parameters $K$, $m$ and $v$ in Eq. (19). Four steel plates were rolled in the four-high mill in Oxelösund and cooled in the equipment for accelerated cooling in order to investigate the austenite grain size. All plates were rolled with short interpass times, in the range of 5-15 [s] between the passes. Their detailed chemical compositions are displayed in Table 1. The silicon content of the steels in the experiments were outside the composition range for Eq. (7) but it is assumed that the equation can be used also for these steels.

The pass schedules for the experiments are shown in Table 2. The reheat temperatures were around $1160^{\circ} \mathrm{C}$.

\subsection{Experiments for the Ferrite Grain Size after TM- rolling}

Another set of experiments was carried out at a laboratory mill at MEFOS $^{29}$ ) where the ferrite grain size was measured after cooling to room temperature. These tests were used to validate the ferrite prediction of the model, which is the crucial item in the model. Table 3 shows the chemical compositions of the rolled specimens and Table 4 shows the pass schedules.

\subsection{Eeasurements of Grain Sizes}

Probes were cut from the full-scale rolled plates in Tables

Table 1. Chemical compositions of the steels (in mass\%) for the austenite grain size experiments.

\begin{tabular}{|c|l|l|l|l|l|l|l|l|}
\hline Case & $\mathbf{C}$ & $\mathbf{M n}$ & $\mathbf{M o}$ & $\mathbf{C r}$ & $\mathbf{N b}$ & $\mathbf{S i}$ & $\mathbf{T i}$ & $\mathbf{V}$ \\
\hline 1 & 0.135 & 1.007 & 0.153 & 0.252 & 0.015 & 0.342 & 0.010 & 0.020 \\
\hline 2 & 0.131 & 1.006 & 0.156 & 0.258 & 0.015 & 0.300 & 0.010 & 0.017 \\
\hline 3 & 0.136 & 0.996 & 0.143 & 0.241 & 0.015 & 0.286 & 0.009 & 0.019 \\
\hline 4 & 0.133 & 1.029 & 0.150 & 0.241 & 0.016 & 0.307 & 0.010 & 0.020 \\
\hline
\end{tabular}

1 and 2. The measurements of austenite grain size were obtained by polishing and etching with Bechet-Beaujard. This reveals the prior austenite grain boundaries. The structures were photographed at locations in the thickness directions that were a quarter of the thickness and in the center of the plates. Five photos were taken on each depth. These pictures were used for a compare analysis and two intercept analyses per probe. The five pictures were compared to standardized pictures of structures, and an average ASTMvalue was received. The mean width and mean height of approximately 100 grains per direction were determined. The measurements gave mean intercept values and corresponding ASTM-value in the horizontal rolling direction and an intercept in the vertical thickness direction, respectively. The average grain size on each depth was also determined as the half of the horizontal intercept plus the half of the vertical intercept.

The image analysis system $\mu$ GOP $2000 /$ s has been used in order to determine the ferrite grain size for the cases in Tables 3 and 4. More than 1100 grains have been measured in each sample. ${ }^{29)}$

\subsection{Calibration of Model}

The full-scale experiments were used to calibrate the full-scale generator. A comparison between measurements of the full-scale experiments and simulations was used in order to determine the parameters $K, m, v$ and $k$ in Eqs. (18), (21). $K=1.3, m=0.65$ and $v=0.67, k=9 \cdot 10 .{ }^{25)}$ After this calibration, no more adjustments of the microstructure model were done. The horizontal, vertical, average and simulated austenite grain sizes for the four different experiments are listed in Table $\mathbf{5}$.

Five pictures were taken from the test pieces and compared on every depth.

The recrystallization regime was only static in number

Table 3. Chemical compositions of the steels (in mass $\%$ ) for the ferrite grain size experiments.

\begin{tabular}{|l|l|l|l|l|l|l|l|l|}
\hline Case & $\mathbf{C}$ & $\mathbf{M n}$ & $\mathbf{M o}$ & $\mathbf{C r}$ & $\mathbf{N b}$ & $\mathbf{S i}$ & $\mathbf{T i}$ & $\mathbf{V}$ \\
\hline 5 & 0.132 & 1.51 & -- & -- & 0.001 & 0.46 & 0.011 & 0.046 \\
\hline 6 & 0.151 & 1.45 & -- & -- & 0.001 & 0.46 & 0.010 & 0.046 \\
\hline 7 & 0.132 & 1.51 & -- & -- & 0.001 & 0.46 & 0.011 & 0.046 \\
\hline
\end{tabular}

Table 2. The basics of the pass schedules in the full-scale experiments on plates in Table 1.

\begin{tabular}{|c|c|c|c|c|c|c|}
\hline Case & $\begin{array}{c}\text { Total } \\
\text { number of } \\
\text { working } \\
\text { passes }\end{array}$ & temperature & $\begin{array}{c}\text { Reheat } \\
\text { thickness } \\
{[\mathrm{mm}]}\end{array}$ & $\begin{array}{c}\text { Final } \\
\text { thickness } \\
{[\mathrm{mm}]}\end{array}$ & $\begin{array}{c}\text { Exit temperature } \\
\text { from the last pass }\end{array}$ & $\begin{array}{c}\text { Time from } \\
\text { furnace to start of } \\
\text { cooling after } \\
\text { rolling }\end{array}$ \\
\hline 1 & 11 & $1169^{\circ} \mathrm{C}$ & 220 & 12.0 & $1027^{\circ} \mathrm{C}$ & $4 \min 6 \mathrm{~s}$ \\
\hline 2 & 12 & $1174^{\circ} \mathrm{C}$ & 220 & 14.0 & $1024^{\circ} \mathrm{C}$ & $4 \min 3 \mathrm{~s}$ \\
\hline 3 & 10 & $1174^{\circ} \mathrm{C}$ & 220 & 12.0 & $1061^{\circ} \mathrm{C}$ & $3 \min 21 \mathrm{~s}$ \\
\hline 4 & 11 & $1167^{\circ} \mathrm{C}$ & 220 & 12.0 & $1013^{\circ} \mathrm{C}$ & $3 \min 35 \mathrm{~s}$ \\
\hline
\end{tabular}


Table 4. The basics of the pass schedules rolled in the four-high reversible rolling mill at MEFOS.

\begin{tabular}{|c|c|c|c|c|c|c|c|}
\hline Case & $\begin{array}{c}\text { Total number } \\
\text { of working } \\
\text { passes }\end{array}$ & Reheat & Slab & Final & Time from start of & Delay time & Reduction \\
temperature & thickness & thickness & rolling to the \\
the & & & & \\
last pass & & & & & & & \\
\hline 5 & 10 & $1160^{\circ} \mathrm{C}$ & $220 \mathrm{~mm}$ & $40.5 \mathrm{~mm}$ & $4 \mathrm{~min} 50 \mathrm{~s}$ & $3 \mathrm{~s}$ & $12.7 \%$ \\
\hline 6 & 10 & $1164^{\circ} \mathrm{C}$ & $220 \mathrm{~mm}$ & $40.4 \mathrm{~mm}$ & $5 \mathrm{~min} 21 \mathrm{~s}$ & $4 \min 17 \mathrm{~s}$ & $13.0 \%$ \\
\hline 7 & 7 & $1150^{\circ} \mathrm{C}$ & $220 \mathrm{~mm}$ & $71.4 \mathrm{~mm}$ & $6 \mathrm{~min} 51 \mathrm{~s}$ & $5 \mathrm{~min} 53 \mathrm{~s}$ & $17.4 \%$ \\
\hline
\end{tabular}

Table 5. The horizontal, vertical, average and simulated austenite grain sizes for the plates.

\begin{tabular}{|c|c|c|c|c|c|}
\hline Case & Depth & $\begin{array}{c}\text { Horizontal } \\
\text { meanintercept } \\
{[\mu \mathrm{m}]}\end{array}$ & $\begin{array}{c}\text { Vertical } \\
\text { meanintercept } \\
{[\mu \mathrm{m}]}\end{array}$ & $\begin{array}{c}\text { Average } \\
\text { meanintercept } \\
{[\mu \mathrm{m}]}\end{array}$ & $\begin{array}{l}\text { Simulated mean } \\
\text { intercept }[\mu \mathrm{m}]\end{array}$ \\
\hline 1 & Center & 26.9 & 23.5 & 25.2 & \multirow[t]{2}{*}{23.0} \\
\hline 1 & $t / 4$ & 21.2 & 21.0 & 21.1 & \\
\hline 2 & Center & 24.5 & 24.7 & 24.6 & \multirow[t]{2}{*}{23.3} \\
\hline 2 & $t / 4$ & 22.5 & 25.3 & 23.9 & \\
\hline 3 & Center & 25.4 & 20.5 & 22.9 & \multirow[t]{2}{*}{25.0} \\
\hline 3 & $t / 4$ & 22.7 & 20.2 & 21.5 & \\
\hline 4 & Center & 24.2 & 20.7 & 22.4 & \multirow{2}{*}{21.5} \\
\hline 4 & $t / 4$ & 20.4 & 16.5 & 18.4 & \\
\hline
\end{tabular}

case 1, 2 and 4 as no precipitation occurred. MDRX occurred after the fifth pass of case 3 . The simulations showed that the temperature has a great influence on the microstructure. It is important that the temperature calculations are accomplished with high precision, to ensure accurate material properties.

\subsection{Validation of Model}

The proposed model is validated by comparing the predicted ferrite grain sizes with the measured ones from the experiments summarised in Tables 3 and 4. The results are also compared with predictions for plate rolling by the program MicDel, listed in. ${ }^{29)}$ The reason for the comparisons with MicDel is that MicDel is established software and is considered as a good method for microstructure analyses. ${ }^{29)}$ The MicDel model is based on semi-empirical equations for volume fraction of recrystallized austenite and recrystallized austenite grain size according to Eqs. (23), (24) and (25):

$$
\begin{aligned}
X & =1-e^{\left(-k_{\text {Middel }}\left(\frac{t}{t_{0.5}}\right)^{n}\right)} \cdots \cdots \\
t_{0.5 \mathrm{SRX}} & =A d_{0}^{a} \varepsilon_{1}^{\mathrm{p}^{\{-b\}}} Z^{-c} e^{\left(\frac{Q_{\text {rex }}}{R T}\right)} \\
d_{\mathrm{SRX}} & =B d_{0}^{d} \varepsilon_{1}^{\mathrm{p}^{-e}}\left(e^{\frac{Q_{\mathrm{d}}}{R T}}\right)^{-f \cdots}
\end{aligned}
$$

Table 6. The measured and simulated ferrite grain sizes for the rolling at MEFOS.

\begin{tabular}{|c|c|c|c|}
\hline Case & $\begin{array}{c}\text { Measured ferrite } \\
\text { grain size }[\mu \mathrm{m}] \text { with } \\
\mu \mathrm{GOP}^{29)}\end{array}$ & $\begin{array}{c}\text { Calculated ferrite } \\
\text { grain size }[\mu \mathrm{m}] \text { with } \\
\operatorname{MicDel}^{29)}\end{array}$ & $\begin{array}{c}\text { Simulated ferrite } \\
\text { grain size }[\mu \mathrm{m}] \text { with } \\
\text { the pass-schedule } \\
\text { generator }\end{array}$ \\
\hline 5 & 14.3 & 9.6 & 12.7 \\
\hline 6 & 14.7 & 8.3 & 12.6 \\
\hline 7 & 12.3 & 10.1 & 14.9 \\
\hline
\end{tabular}

where $X$ is the volume fraction of recrystallized austenite at the time $t$ after deformation, $t_{0.5 \mathrm{SRX}}$ is the time for $50 \%$ static recrystallization, $d_{\mathrm{SRX}}$ is the recrystallized austenite grain size. The constants $k_{\text {MicDel }}, n, A, a, b, c, B, d, e$ and $f$ are unique for each steel and dependent on its chemical composition. The pass schedule and the material coefficients for recrystallization are given in the input. The output is the calculated average austenite grain size and the ferrite grain size. ${ }^{30)}$ MicDel was practically applied on different kinds of steels with series of fitting parameters gained from laboratory results. The result is listed in Table 
Table 7. Simulated results by the pass-schedule generator.

\begin{tabular}{|c|c|c|c|c|}
\hline Austenite grain size at start of ACC $[\mu \mathrm{m}]$ & 29.8 & 24.1 & 13.1 & 10.9 \\
\hline Ferrite grain size $[\mu \mathrm{m}]$ after ACC & $\dot{T}=[5 / \mathrm{s}]: 25.0$ & $\dot{T}=[5 / \mathrm{s}]: 21.3$ & $\dot{T}=[5 / \mathrm{s}]: 5.39$ & $\dot{T}=[5 / \mathrm{s}]: 5.26$ \\
& $\dot{T}=[10 / \mathrm{s}]: 20.4$ & $\dot{T}=[10 / \mathrm{s}]: 17.2$ & $\dot{T}=[10 / \mathrm{s}]: 4.22$ & $\dot{T}=[10 / \mathrm{s}]: 4.09$ \\
\hline Accumulated strain before ACC $[--]$ & 0 & 0 & 0.639 & 0.635 \\
\hline Number of passes before delay time & -- & 8 & 5 & 4 \\
\hline Length of the delay time [min] & -- & 1 & 5 & 10 \\
\hline Finishing rolling temperature & $1092^{\circ} \mathrm{C}$ & $982^{\circ} \mathrm{C}$ & $929^{\circ} \mathrm{C}$ & $895^{\circ} \mathrm{C}$ \\
\hline Total number of passes & 8 & 8 & 9 & 10 \\
\hline Type of rolling schedule & SRX+MDRX & SRX+MDRX & SRX+PRE+MDRX & SRX+PRE+MDRX \\
\hline
\end{tabular}

6. That should be pointed out, that the initial austenite grain size $d_{0}=20[\mu \mathrm{m}]$ in the MicDel-calculations. ${ }^{29)}$ The used value of $200[\mu \mathrm{m}]$ in the current developed software is more reasonable as the reheat temperature was in the same range as at normal full-scale rolling. MicDel calculates a finer ferrite grain size than the pass-schedule generator. The assumed finer initial austenite grain size in Ref. 29) contributes to finer final grain size. The pass-schedule generator results in finer grain size for the two $40 \mathrm{~mm}$ plates and coarser grain size for the $70 \mathrm{~mm}$ plate than measured. On the whole, the results from the proposed model in this investigation are in good agreement with the $\mu \mathrm{GOP}$-measurements and even better than the MicDel-results.

\section{Application of Model}

Pass-schedules for a slab of initial thickness $220 \mathrm{~mm}$ that should be given a final thickness $20 \mathrm{~mm}$ and width $2196 \mathrm{~mm}$ were determined by the roll pass scheduler as a demonstrator case. The chemical analysis was the same as for case 3 in the full-scale experiments. The reheat temperature was simulated as $1174^{\circ} \mathrm{C}$. One pass-schedule without any long interpass time was also simulated as a reference case. The results are compiled in Table 7. Different length of the long interpass time were tested and also the amount of the pre-deformation before the long interpass time. The maximal length of this time was set to ten minutes and placed after the fourth pass. After rolling, two cooling rates are used, $\dot{T}=5\left[{ }^{\circ} \mathrm{C} / \mathrm{s}\right]$ and $\dot{T}=10\left[{ }^{\circ} \mathrm{C} / \mathrm{s}\right]$. The latter corresponds to the ACcelerated Cooling (ACC) procedure. The plates rolled with five or ten minutes long delay time are affected of precipitation during the delay time and MDRX in the finishing rolling. This contributes to the very fine ferrite grains in these cases. It can be seen that the smallest ferrite grain size is predicted for the case with four passes before the delay time and using a length of ten minutes. The decrease in temperature due to a long pause leads also to higher rolling forces. This requires more roll passes with less reduction in each pass. One can also observe, that even a pause length of one minute results in smaller ferrite grains compared to the reference pass schedule. Thus, the results show that the amount of pre-deformation and the

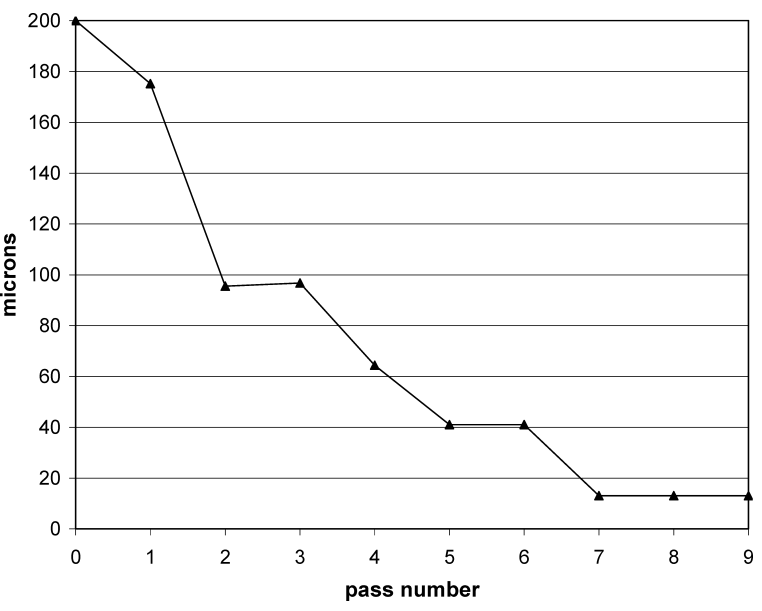

Fig. 3. The austenite grain size after every pass in the TM-pass schedule for the plate with 5 min long delay time. The initial austenite grain size is $200 \mu \mathrm{m}$ before the first pass.

delay time should be carefully chosen, to avoid unnecessary low productivity or on the other hand, to ensure a proper ferrite grain size in the finish rolled material. The software gives the possibility to find a length of the interpass time that reduces grain size without increasing the forces so that maximum reduction can not be applied in each pass. Figure 3 illustrates how the austenite grain size changes during the TM-pass schedule for the plate with $5 \mathrm{~min}$ long delay time. The austenite grain size decreases rapid after the first passes, during the delay time grain growth occurs and the precipitation reaches $5 \%$. MDRX occurs in the second pass after the delay time.

\section{Discussion}

The proposed roll pass scheduler is an improvement of existing software for planning of roll pass schedules at the heavy plate mill at SSAB in Oxelösund. The software consists of a number of more or less advanced models. The proposed models for the material behavior were chosen from different sources, in order to obtain accurate description for the actual steel grades. The motivation for the development of the software is the need for a code that is pos- 
sible to use on-line. Therefore, the existing MicDel was not an alternative for the complete investigation. Moreover, neither precipitation of $\mathrm{Nb}(\mathrm{C}, \mathrm{N})$ nor MDRX are considered in MicDel. The model for the yield limit in Eq. (3) is important for the force calculations. It is obvious that it does not contain any direct influence of the austenite grain size. There are also open issues about the effect of precipitation on the recrystallisation.

Cho and co-workers observed that precipitation could not prevent dynamic recrystallization. ${ }^{26)}$ The precipitation model and Eq. (12) were extrapolated for some steel grades in the investigation with respect to the compositions of $\mathrm{Mn}$ and $\mathrm{Si}$. The used models are however more accurate than then original model proposed of Dutta and Sellars in Ref. 25) The models were tested on a number of chemical compositions in Ref. 9) with acceptable results.

The model assumes homogenous and isotropic conditions over the thickness of the plate and only predicts one grain size. In reality the austenite grain sizes vary over the thickness of the plate. They are also more elongated in the rolling direction. However, the observed variations are small in the most cases, see Table 5. Zheng established that uniform and fine ferrite grains of $6 \mu \mathrm{m}$ can be achieved using recrystallization controlled rolling. ${ }^{14)}$ Morrison $^{2)}$ found out that ferrite grain sizes of $\sim 5 \mu \mathrm{m}$ may be obtained in thin plates of commercially controlled-rolled micro alloyed steels. ${ }^{2}$

This investigation demonstrates in Table 7 the difficulty to reach a fine-grained ferrite microstructure. Achieving a ferrite grain size of 5-6 $\mu \mathrm{m}$ needs a careful investigation of the pass-schedule before the full-scale production starts, to secure proper ferrite grain size and avoid unnecessary low productivity due to long delay time. Longer delay time and lower finishing rolling temperature promotes finer ferrite grain size.

\section{Acknowledgements}

Jernkontoret the Swedish Steel Producers' Association, and the Knowledge Foundation which both supported the project, are fully acknowledged.

\section{REFERENCES}

1) B. Ahlblom: Proc. of Stålindustrins värmnings-bearbetnings och materialpaket 1999-2003, report D 797, project 31042, Swedish Steel Producers' Association, Stockholm, (2003), 4.

2) W. B. Morrison and J. A. Chapman: Controlled rolling, GS/PROD/MISC/107/75/C, British Steel Corporation, (1975), 1.

3) A. Köthe, J. Richter, A. Güth, L. Kaun, G. Backmann, M. Schaper and U. Gutteck: Recrystallization-controlled rolling of $\mathrm{C}-\mathrm{Si}-\mathrm{Mn}-$
V-N steel, Institut für Festkörper- und Werkstofforschung Dresden, Germany, (1989).

4) B. Leden: User's Manual STEELTEMP ${ }^{\circledR}$, MEFOS Metal Working Research Plant, Sweden, (1997).

5) J. Levén: User's Manual CROWN426, MEFOS Metal Working Research Plant, Sweden, (2004).

6) T. Nilsson, P. Huml, U. Ståhlberg, T. Engelbert, S. Essle, K. Larsson and U. Öhman: Massivomformning, Verkstadstekniska Processer, Tribologi, Formelsamling, Institution for Metal Working, Royal Institute of Technology, Stockholm, (1986).

7) T. Senuma and H. Yada: Proc. of Int. Symp. on Accelerated Cooling of Rolled Steel, Pergamon Press, New York, (1988), 105.

8) J. G. Beese: Iron Steel Eng., 57 (1980), 49.

9) F. Sicilliano and J. J. Jonas: Metall. Mater. Trans. A, 31A (2000), 511.

10) C. M. Sellars and J. A. Whiteman: Met. Sci., 13 (1979), 187.

11) R. Abad, A. I. Fernandez, B. López and J. M. Rodriguez-Ibabe: ISIJ Int., 41 (2001), 1373.

12) C. M. Sellars: Mater. Sci. Technol, 6 (1990), 1072.

13) T. Siwecki and G. Engberg: Proc. of Thermo-Mechanical Processing in Theory, Modelling \& Practice, [TMP] exp 2, Swedish Society for Materials Technology, Stockholm, (1997), 121.

14) Y. Z. Zheng, A. J. DeArdo, R. M. Fix and G. Fitzsimons: Proc. of HSLA Steels, Technology and Applications, American Society for Metals, Materials Park, OH, (1984), 85.

15) J. Zrnik, T. Kvackaj, A. Pongpaybul, P. Srcharoenchai, J. Vilk and V. Vrovinsky: Mater. Sci. Eng. A, A319-321 (2001), 323.

16) A. I. Fernandez, P. Uranga, B. López and J. M. Rodriguez-Ibabe: ISIJ Int., 40 (2000), 899.

17) S. I. Kim, Y. Lee, D. L. Lee and Y. C. Yoo: Mater. Sci. Eng., $\mathbf{A 3 5 5}$ (2003), 390.

18) A. I. Fernandez., P. Uranga, B. López and J. M. Rodriguez-Ibabe: Mater. Sci. Eng., A261 (2003), 367.

19) C. M. Sellars: Proc. of Int. Conf. Hot Working and Forming Processes, Met. Soc., London, (1980), 440.

20) C. P. Hong and J. J. Park: Mater. Proc. Technol., 143-144 (2003), 759.

21) L. P. Karjalainen, T. M. Maccagno and J. J. Jonas: ISIJ Int., 35 (1995), 1523.

22) K. Minami, F. Siciliano, T. M. Maccagno and J. J. Jonas: ISIJ Int., 36 (1996), 1507.

23) Y. T. Zhang, D. Z. Li and Y. Y. Li: Acta Metallurgica Sinica, 15 (2002), 267.

24) R. K. Gibbs, B. A. Parker and P. D. Hodgson: Proc. of Int. Symp. on Low-Carbon Steels for the 90's; Recrystallization '90, ed. by T. Chandra, The Minerals, Metals \& Materials Society, USA, (1993), 173.

25) B. Dutta and C. M. Sellars: Mater. Sci. Technol., 3 (1987), 197.

26) S. H. Cho, K. B. Kang and J. J. Jonas: ISIJ Int., 41 (2001), 63.

27) K. J. Irvine and F. B. Pickering: J. Iron Steel Inst., 205 (1967), 161.

28) D. Q. Bai: PhD Thesis, McGill University, Montreal, (1995), 28.

29) T. Siwecki and O. Wang: Microstructure evolution during energy saving heavy plates RCR rolling of $\mathrm{Ti}-\mathrm{V}$ microalloyed steel, Research Report no: IM-2003-565, Swedish Institute for Metals Research, Stockholm, (2003), 1.

30) P. Hansson: PhD. Thesis, Institution for industrial production, Royal Institute of Technology, Stockholm (2004), 45. 